Vista general aérea de la esclusa de $\mathrm{Pe}$ tershagen y canales de entrada y salida.

Una fase del hormigonado de la esclusa de Schlusselburg, utilizando encofrados mó viles.

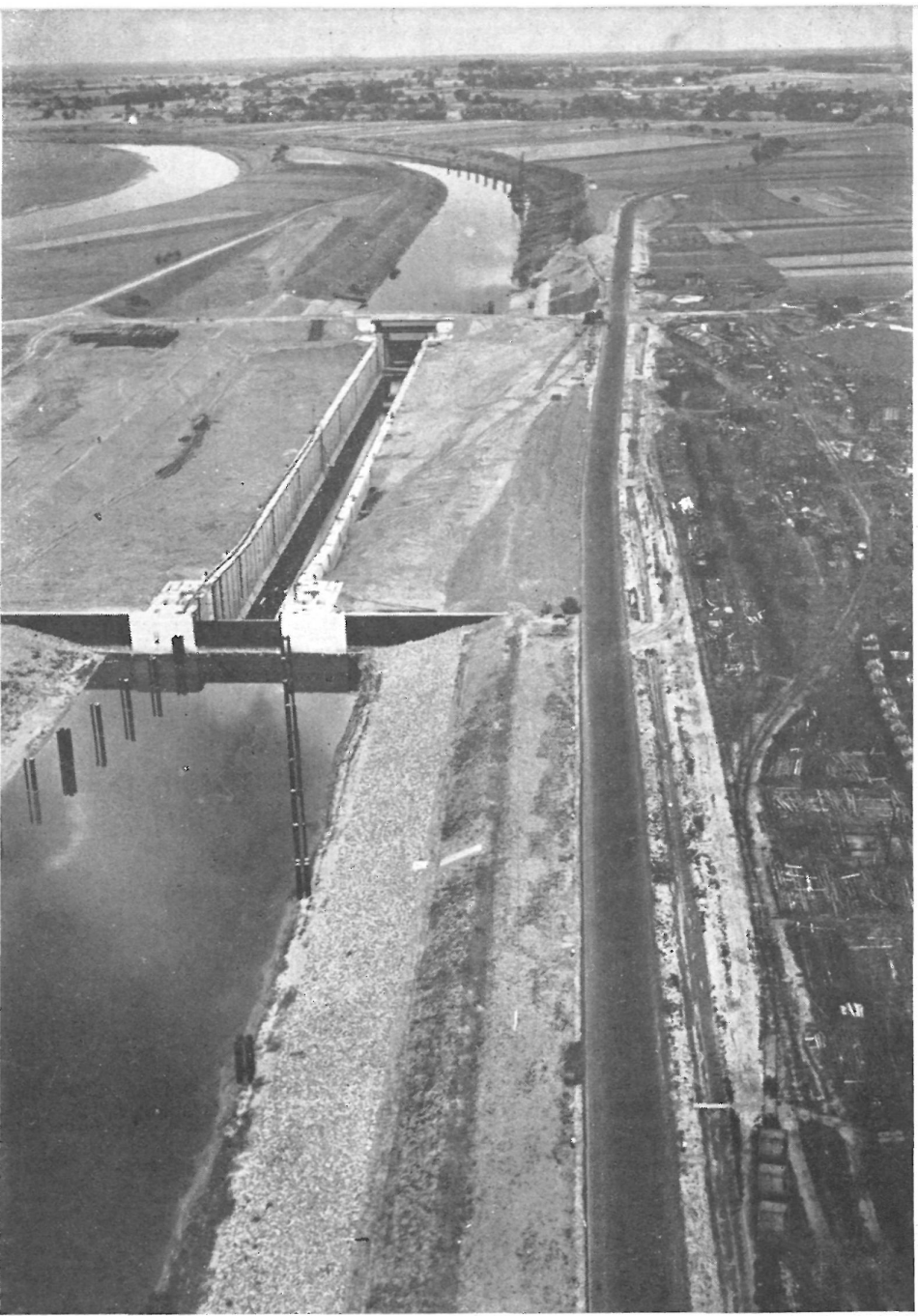

\title{
canalización y aprovechamientos del río WESER
}

H. WURFEL, ingeniero

El tramo inferior del río Weser, situado en la provincia de Hannover (Alemania) en su mayor parte, de unos $160 \mathrm{~km}$ de longitud, presenta un cauce muy tortuoso y de bastante desnivel.

La navegación fluvial en este río, principalmente entre Bremen y Minde, tramo al que nos referimos en este trabajo, ha venido experimentando un aumento progresivo, ya que se halla unido con otras importantes arterias fluviales y dentro de una zona industrial.

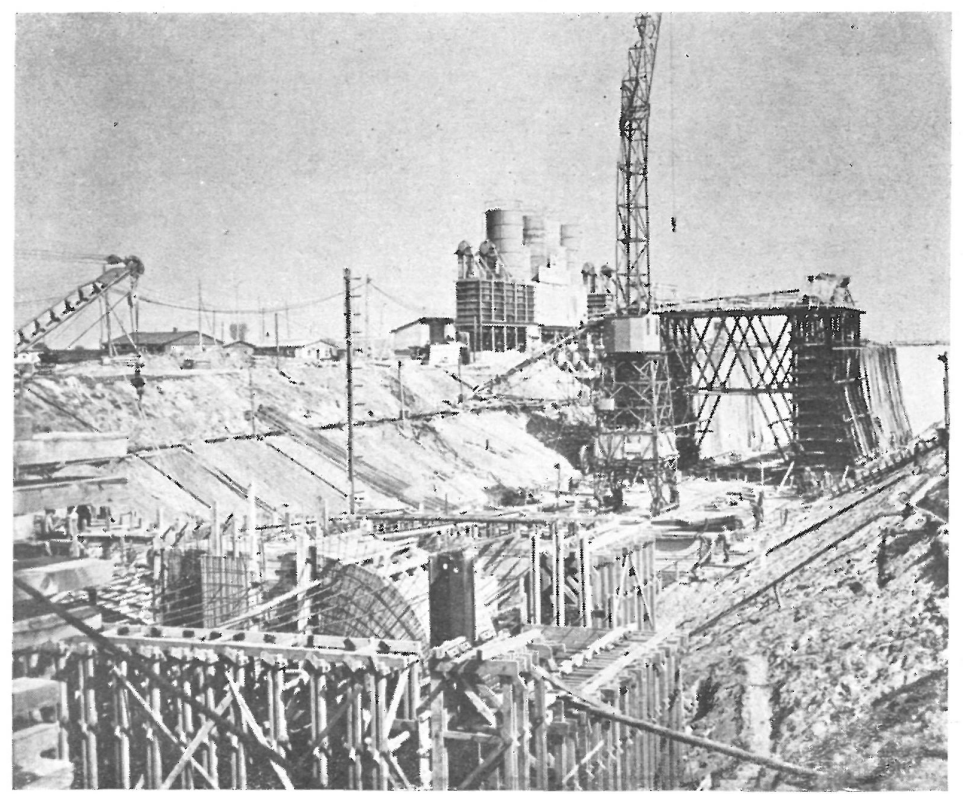




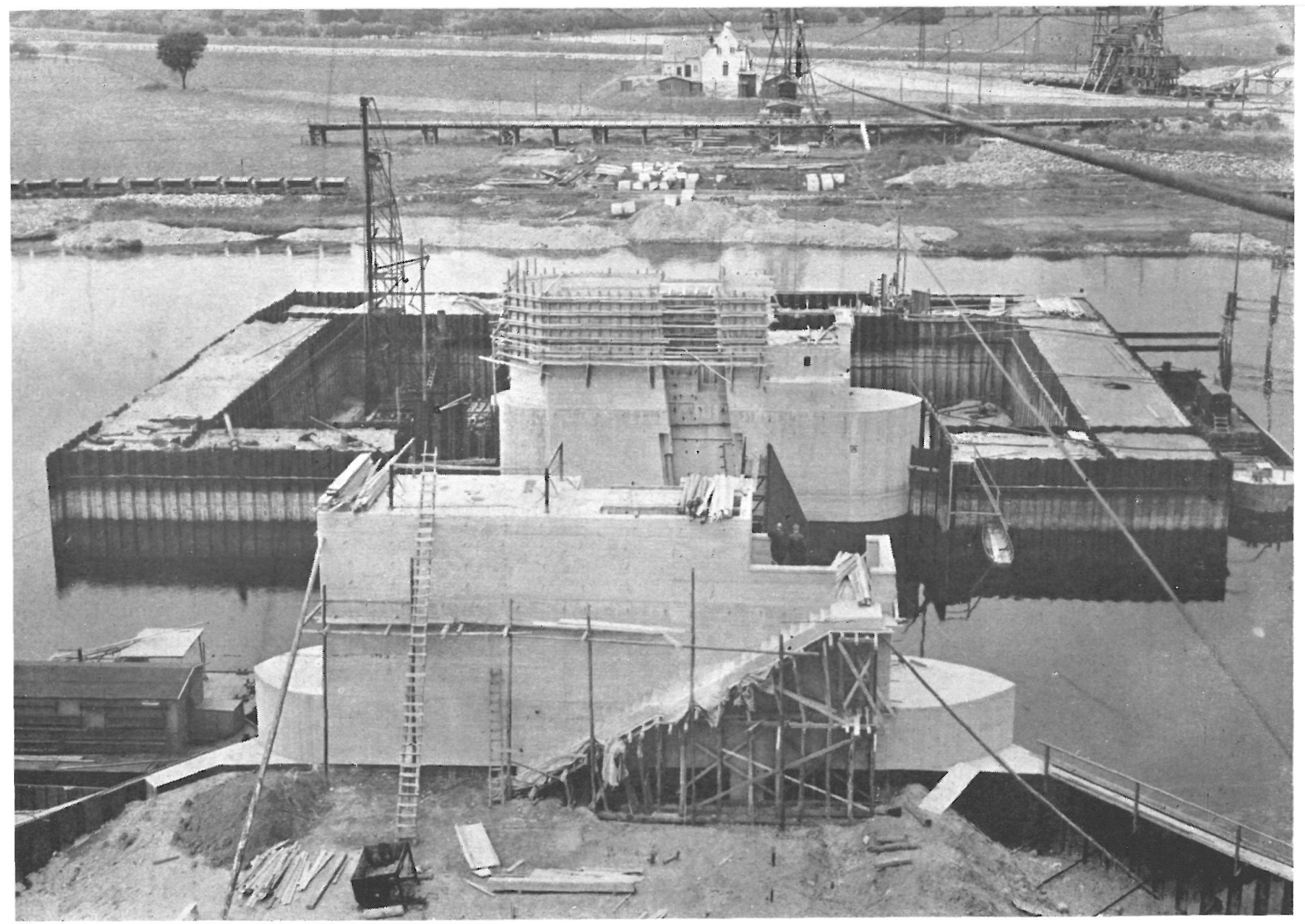

Construcción de las pilas que separan los tramos de paso de aguas Petershagen.

Construcción de ración de la central de Schlusselburg.

Presa y central hidroeléctrica de Petershagen.
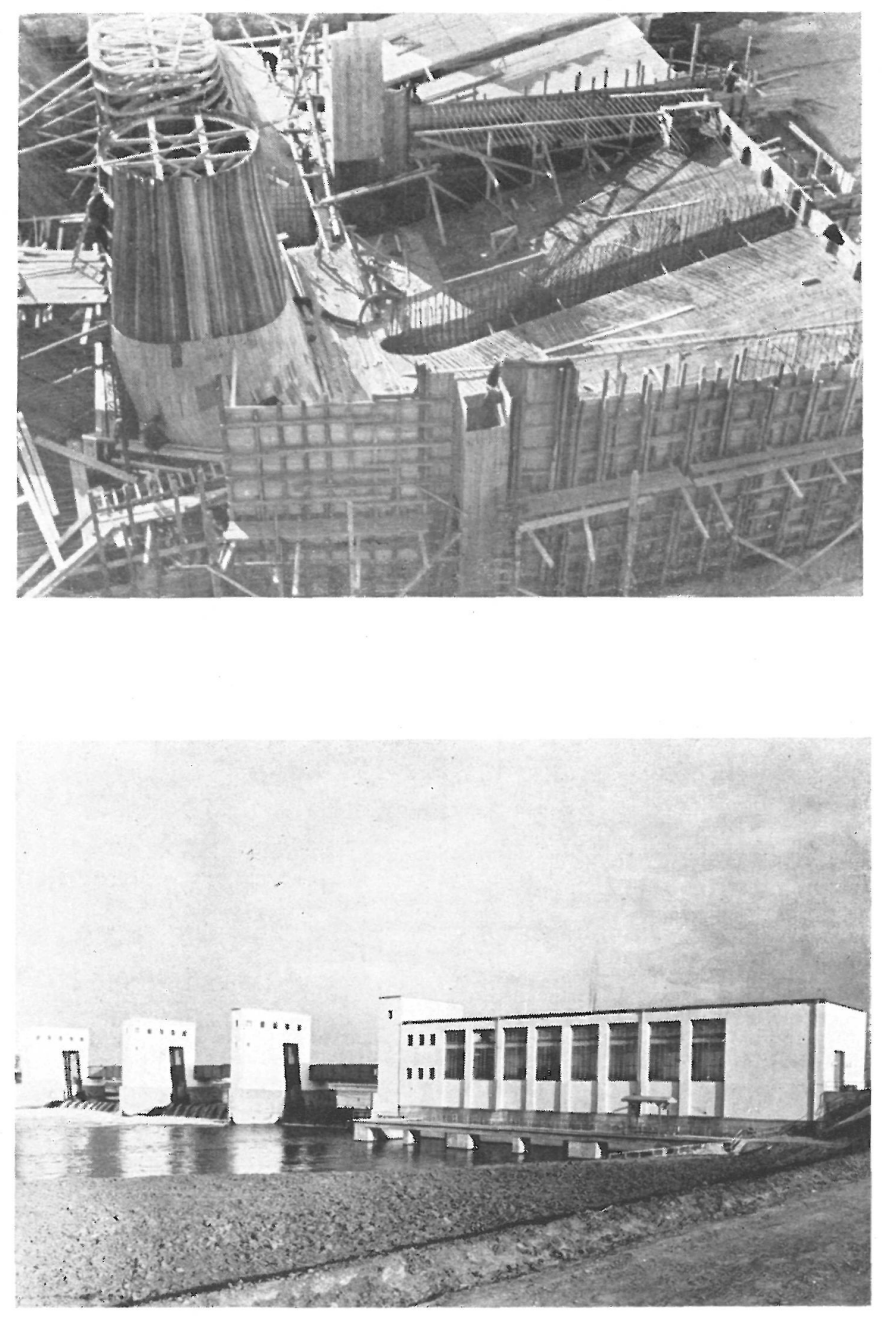

Para la corrección de los grandes codos que caracterizan el cauce de este río, reduciendo la distancia entre Bremen y Minde, así como para la construcción de centrales hidroeléctricas y nuevos puentes, se hizo un estudio general de este tramo del Weser, del que se llegó a un proyecto ambicioso de nuevas construcciones hidráulicas, esclusas, etc.

Muchas de estas obras han sido terminadas, y otras se hallan en vías de realización.

En la ejecución de estas obras se han empleado métodos constructivos modernos, y los trabajos se han realizado auxiliándose de medios auxiliares potentes.

INFORMES DE LA CONSTRUCCION 90 